\title{
Cernuda y Gil de Biedma: monologando la cruda verdad
}

\section{Cernuda and Gil de Biedma: monologizing the harsh truth}

Cristhian Geovany Sarango Jaramillo ${ }^{1}$

\section{Resumen}

El presente trabajo tiene como objetivo analizar el uso del monólogo dramático en dos poemas "Soliloquio del farero" del poemario Invocaciones (1934-1935) de Luis Cernuda y "Contra Jaime Gil de Biedma” de libro Poemas póstumos (1968) de Jaime Gil de Biedma.

En los poemas antes mencionados, vemos la prevalencia de esta técnica poética, la cual busca representar al objeto lírico en primera persona, transmitiendo una serie de emociones que los autores señalados muestran en sus creaciones. Cernuda refleja la soledad en su máxima expresión al describir en su farero (poeta) a un sujeto solitario, por otra parte, Gil de Biedma exterioriza la lucha del "yo supremo", el cual busca la supervivencia en un mundo moderno.

Palabras clave: Monólogo dramático; "Soliloquio del farero"; Soledad; Luis Cernuda; "Contra Jaime Gil de Biedma”; supervivencia.

\section{Abstract}

The objective of this work is to analyze the use of the dramatic monologue in two poems "Soliloquio del farero" from Luis Cernuda's poems book named Invocations (1934-1935) and "Contra Jaime Gil de Biedma" from Poemas Póstumos Book (1968) by Jaime Gil de Biedma.

In the aforementioned poems, we see the prevalence of this poetic technique, which seeks to represent the lyrical object in the first person, transmitting a series of emotions that the authors indicated show in their creations. Cernuda reflects solitude in its maximum expression when describing in its keeper (poet) a solitary subject, on the other hand, Gil de Biedma externalizes the struggle of the "supreme self", which seeks survival in a modern world.

Keywords: Dramatic monologue; "Soliloquio del farero"; Loneliness; Luis Cernuda; "Against Jaime Gil de Biedma”; survival.

1 Máster en Literatura Española. Docente investigador de la Sección Lenguas Hispánicas y Literarias de la Universidad Técnica Particular de Loja. Correo: cgsarango@utpl.edu.ec, https://orcid.org/oooo-0003-1303-7702

Recibido: 27/01/2019 Aprobado: 20/06/2019 


\section{HUMANIDADES}

\section{Introducción}

Este trabajo tiene como objetivo estudiar el uso del monólogo dramático en los poemas "Soliloquio del farero" de Luis Cernuda y "Contra Jaime Gil de Biedma" de Jaime Gil de Biedma.

Si bien es cierto el monólogo dramático surge a inicios del siglo XX por T.S. Elliot, Tennyson y Browning, entre otros en Inglaterra, nuestro planteamiento pretende analizar como la Generación de los 50 (Gil de Biedma y Luis Cernuda), a través de los poemas: "Soliloquio del farero" y "Contra Jaime Gil de Biedma" muestran a un personaje alegórico, el cual les permite expresar indirectamente sus emociones de un mundo lacerante.

Por lo tanto, nuestro interés radica en presentar dicha técnica poética, como un recurso frecuente en la poesía de los autores antes mencionados, concretamente, en las composiciones: "Soliloquio del farero" y "Contra Jaime Gil de Biedma".

\section{Desarrollo}

La relación más evidente entre Jaime Gil de Biedma y Luis Cernuda es la gran admiración que tenía el primero por el segundo. Poeta español de la generación del 50, Biedma, junto con otros "poetas del conocimiento" como José Ángel Valente, encontró en Cernuda una pieza clave para la renovación de la literatura española, como lo señala en uno de sus ensayos sobre el escritor sevillano, "Como en sí mismo, al fin" (1977):

Hubiera sido incapaz de comprender adónde apuntaba Valente diciéndome que Cernuda, entre todos los poetas del veintisiete, era el más próximo a lo que nosotros intentábamos hacer. Creo que los años siguientes confirmaron la exactitud de su apreciación. La proximidad era genuina, consistía en algo más que en personales afinidades — de temperamento poético en Brines, de admiración por la tradición poética inglesa en Valente y en mí-, porque se percibía asimismo en otros poetas compañeros nuestros, y desde antes de 1958 (p. 344).

A más del interés en la tradición poética inglesa de la que Cernuda toma el recurso del monólogo dramático, Biedma señala un interés común en utilizar la experiencia como punto de partida del discurso poético:

Si Cernuda asume la realidad de la experiencia común y de la propia identidad vecinal sin reconocerse en ellas, nosotros, en nuestra poesía, intentábamos asumir una y otra, para reconocernos. El punto de partida era el mismo y los extremos se tocan. Ambos postulan un modo semejante de concebir y realizar el poema" (p. 345). 
Esta afinidad se ve reflejada, sin desatender a sus diferencias, en los dos poemas que se analizan aquí: "Soliloquio del farero", Invocaciones, (1934-1935) de Luis Cernuda, y "Contra Jaime Gil de Biedma”, Poemas póstumos, (1968) de Jaime Gil de Biedma; teniendo como base el uso del monólogo dramático por parte de ambos poetas.

La existencia de esta forma poética se legitima al cumplir el texto con sus rasgos característicos generalmente señalados por la crítica: "El hablante es un personaje creado por el poeta; el personaje habla en primera persona y se dirige a un interlocutor o un público concreto; se trata de un momento y un lugar específicos, muchas veces un instante crítico" (Gottlieb, 2014, p. 23).

En el "Soliloquio del farero" se evidencia una forma cercana, una aproximación a la modalidad lírica del monólogo dramático, debido a la fuerte cercanía entre el poeta y su personaje, así como a la ausencia de los elementos del drama. Así se aproxima, mas no es un monólogo dramático per se "puesto que encierra dos de los fundamentos básicos [...] esto es, hablante e interlocutor" (Thanoon, 1991, p. 114), pero descuida los citados arriba.

Este poema corresponde a la obra poética de madurez cernudiana y tiene como eje la paradoja entre la realidad y el deseo como testimonio existencial del autor, ya que parte de sus vivencias como exiliado político y su condición homosexual, aunque presenta la experiencia "como si no fuera suya" (Thanoon, 1991, p. 111).

Desde el aspecto formal, en el "Soliloquio del farero" se evidencia el "abandono de la composición breve y la incursión en el poema extenso” (Thanoon, 1991, p. 110), el texto se compone de 66 versos libres, que alternan entre heptasílabos, endecasílabos y alejandrinos. La estructura del poema está divida en tres momentos que corresponden a la niñez (vv. 1-10), juventud (vv. 11-29) y madurez (vv. 30-66).

La soledad como interlocutor y el deseo del poeta de trascenderla, son dos líneas de sentido presentes en este texto. Cernuda no inventa un mundo fantástico, sino que cuenta y exalta su estado solitario, motivado por un hecho objetivo real: su desacuerdo con el mundo que le circunda. El argumento de "Soliloquio del farero" tiene como punto de partida la reacción de un "hombre dedicado al oficio de farero que, habiendo fracasado en la experiencia amorosa, busca en la soledad su única compañera fiel" (Sáez Aragón, 1988, p. 214).

Desde los versos 1 y 2 es claro que se trata de un diálogo "cuya finalidad no es la comunicación mutua, sino la autoexposición del yo, puesto que se dirige a interlocutores pasivos" (Thanoon, 1991, p. 110); la voz poética, el farero, se dirige a un tú que es la soledad: "Cómo llenarte, soledad, / sino contigo misma". A pesar de que el personaje que habla es el farero, no es difícil identificarlo como metáfora del propio poeta, aislado de los hombres, alumbrando a la humanidad con su poesía. En el verso 
3 aparece la referencia a la infancia: "De niño, entre las pobres guaridas de la tierra", el farero se ampara en la soledad manteniéndose "quieto en ángulo oscuro" (v. 4). En el quinto verso el poeta dice que la soledad es "encendida guirnalda", es decir, la luz que le permite realmente ver a su alrededor. En el verso 6 "mis auroras futuras y furtivos nocturnos" se construye una aliteración en los fonemas /f/, /t/, /r/ y /u/. En el séptimo verso "y en ti los vislumbraba", la esperanza vivificadora de buscar una redención en la soledad, por lo que, en el octavo verso hay un encabalgamiento con el anterior "naturales y exactos, también libres y fieles". Entre los versos 9 y 10 hay un paralelismo entre "semejanza mía” y "a semejanza tuya”, para cerrar esta sección con una identificación del farero/voz poética con la soledad.

El segundo momento empieza en el verso 11 y termina en el 29. Esta concordancia da una "idea argumental: negación y huida de la soledad, búsqueda de la solución en la compañía a 'los viejos placeres prohibidos”' (Sáez Aragón, 1988, p. 218). En esta segunda parte el hablante lírico trata de huir de la soledad buscando relaciones con los hombres, pero siempre sintiéndose diferente a ellos: "Me perdí luego por la tierra injusta / Como quien busca amigos o ignorados amantes; Diverso con el mundo, / Fui luz serena y anhelo desbocado"; una lejanía evidente y necesaria.

El verso decimonoveno "y al velarse a mis ojos" invita a juntarse "con nubes sobre nubes de otoño desbordado"; el otoño es el punto de encuentro entre el pasado solitario de su niñez y el futuro inmediato de soledad de su juventud que se hace evidente. En el verso vigésimo primero "la luz de aquellos días en ti misma entrevistos", hay una personificación que sugiere la búsqueda de la luminosidad como un camino para alejarse de la soledad y que confluye en una paradoja puesto que el farero trabaja con la luz. Con el verso "Te negué por bien poco", inicia una enumeración para volver al tema de las diferentes relaciones con las que quiso escapar infructuosamente de la soledad: "Por menudos amores ni ciertos ni fingidos, / Por quietas amistades de sillón y de gesto, / Por un nombre de reducida cola en un mundo fantasma", y en los versos "Por los viejos placeres prohibidos, /Como los permitidos nauseabundos", se haya una alusión a la orientación sexual del poeta, que fue una de las causas de su soledad y de su aislamiento social. Finalmente, esta sección culmina señalando la hipocresía de la gente: "otiles solamente para el elegante salón susurrado / en bocas de mentira y palabras de hielo" (vv. 28, 29).

En la tercera parte, la voz poética se sitúa en el momento presente desde el que regresa a ver a la persona que fue antes. Entre los versos 36 y 38, el poeta "entabla comunicación con elementos naturales" (Thanoon, 1991, p. 110) como el sol, la lluvia, el bosque, el mar y, sobre todo, la soledad, que son los que le permiten reencontrarse limpio de todo deseo. La soledad aparece como un "cuerpo oscuro y esbelto" que acompaña la vida del poeta. 
A partir del verso 44 se presenta la imagen del farero/poeta como luz señaladora para los hombres "soy en la noche un diamante que gira advirtiendo a los hombres". Y en los versos finales, compara la soledad con una "transparente pasión" (v. 58), con un "inmenso abrazo" (v. 59) y con los elementos naturales "el sol, el mar, / La oscuridad, la estepa" (v. 6o), él y la soledad son uno solo en una codependencia natural e irreductible, la misma que se construye entre el ser/soledad y la distancia con sus semejantes, obligada y benigna, porque solo desde la soledad y la distancia, este encuentra el amor hacia sus semejantes: "Por ti, mi soledad, los busqué un día; / en ti, mi soledad, los amo ahora" (vv. 65,66).

Es notorio entonces, en este poema, el hecho de que el autor dibuje a un personaje (el farero) para proyectar en él su voz y sus sentimientos, tal como lo habían hecho antes poetas ingleses como Robert Browning (Cernuda, 1958, p. 396), Wordsworth y Coleridge (Gil de Biedma, 1977, p. 348). Este recurso constituye una novedad en la poesía de Cernuda porque, como se ha expresado antes, el hablante es el farero y el interlocutor es la soledad, así "el yo emisor es el del poeta, que dirige a un interlocutor mudo un mensaje sobre ese mismo interlocutor" (Pérez Parejo, 2006).

De la misma manera, esta innovación de Cernuda influyó en la poesía de Jaime Gil de Biedma, en concreto en el poema "Contra Jaime Gil de Biedma", donde se hace evidente el uso de las características propias del monólogo dramático expresadas en líneas anteriores y que el poeta domina de forma ejemplar, incluso hasta crear la ilusión de construir uno, usando solo algunos de sus rasgos en la composición.

En este texto hay dos motivos similares a los que encontramos en el "Soliloquio del farero" de Cernuda, el personaje ve al que fue en su juventud y habla sobre su pasado. Sin embargo, en este caso, hay un desdoblamiento del propio yo, pues hablante e interlocutor son la misma persona, en dos etapas distintas de la vida; como señala Thanoon (1991): "supone otra aportación destacable en el empleo del monólogo dramático. El poema lleva la técnica del desdoblamiento del 'yo' a su máxima consecuencia dramática, es decir, enfrenta las dos caras de una sola personalidad como si fueran dos individuos independientes" (p. 427).

Respecto a su estructura, encontramos cinco estrofas de once versos cada una con una medida fluctuante. A pesar de no haber una rima constante, aparece una rima asonante dispersa (e-o) en negro, cacaseno, espejo, increpo, hacerlo.

En el plano morfosintáctico, son abundantes los sustantivos y adjetivos ("calles muertas", "cara destruida", "muchacho soñoliento", "impresión confusa"), que indican objetivismo y especificación, además de ser imágenes de una evidente obscuridad, aquella que desea mostrar el poeta para acentuar el aspecto dramático de su monólogo. 
El desdoblamiento de persona se evidencia con el uso de los determinantes posesivos y pronombres personales ("tú", "te", "me", "mi reputación", "mis trajes"). Los verbos son numerosos por lo que representan el dinamismo y reflexión de este monólogo dramático. Es llamativo el uso del infinitivo (cambiar, dejar, renunciar) de la primera estrofa para representar acciones absolutas frente a los gerundios de la última estrofa (muriendo, tropezando), que representan eternidad y permanencia en el tiempo.

Son relevantes, también, las enumeraciones (v. 13), el polisíndeton "y la desesperanza y la impaciencia y el resentimiento" y los encabalgamientos "confusa de pánico", "muebles a tientas", para reproducir un ritmo exaltado y extenuante.

"Temáticamente, el poema se divide en dos partes: una primera parte (cuatro primeras estrofas), en las que se pone de manifiesto, a través de un desdoblamiento, a un ser acabado por el paso del tiempo y sus vicios, al que se ataca de forma violenta y a quien se le reprocha sus acciones. En la segunda parte (quinta estrofa), el propio Gil de Biedma, al humanizarse, se resigna y se siente obligado a "amarse a sí mismo".

La primera estrofa inicia con un tono interrogante y de imprecación hacia el otro, utilizando un lenguaje elevado, le llama: "pelmazo, / embarazoso huésped, memo vestido con mis trajes, / zángano de colmena, inútil, cacaseno” (vv. 7-10).

En la segunda estrofa se describe la vida de bohemio de la que se había introducido en el verso 6 y aparecen estas palabras: bares, noche, chulos, floristas, madrugada, borracho. Estos términos recuerdan a "los placeres prohibidos" de la juventud del farero de Cernuda. Los versos que cierran la estrofa ponen en evidencia que se trata de un yo maduro hablando con ese otro, frente al espejo de su pasado.

La tercera estrofa hace referencia a la gracia de la juventud perdida y, al darse cuenta de aquello, el interlocutor se queda desarmado "verdadero huérfano" (v. 32).

En la cuarta estrofa, nuevamente hay una imprecación, pero esta vez el hablante usa un lenguaje soez, coloquial (v. 34) y un paralelismo "que tú eres fuerte cuando yo soy débil/ y que eres débil cuando me enfurezco" (v. 36, 37), para reproducir sus inherentes contradicciones.

Finalmente, en la quinta estrofa el hablante lleva a la cama al interlocutor, van "torpemente abrazados" (v. 51) y se resigna a la innoble servidumbre de tener que "amarse a sí mismo" (v. 55).

En este texto, Gil de Biedma presenta el conflicto del desdoblamiento de conciencia mostrando las dos caras de una misma personalidad y nos da una pauta del sentido que la poesía tiene para él: 
Pensaba yo que la fundamental experiencia del vivir está en la ambivalencia de la identidad, en esa doble conciencia que hace que me reconozca — simultánea o alternativamente- uno, unigénito, hijo de dios, y uno entre otros tantos, un hijo de vecino. El juego de esas contrapuestas dimensiones de la identidad, que sólo en momentos excepcionales logran reposar una en otra, que incesantemente se espían y se tienden mutuas trampas, cuando no se hallan en guerra abierta, configura decisivamente nuestra relación con nosotros mismos y nuestras relaciones con los demás. Era esa la experiencia, creía yo, que debe servir como supuesto básico de todo poema contemporáneo (Gil de Biedma, 1977, p. 341).

Si bien, Gil de Biedma se inspira en el monólogo dramático de Cernuda, está más cercano al de Eliot, puesto que la propuesta cernudiana es construir una voz que dialoga con otros, con un colectivo; en el caso de Gil de Biedma la preocupación es altamente individual; sin embargo, esta poesía no es un soliloquio o un monólogo dramático tradicional, sino que le permite al poeta contemplar desde afuera sus dos conciencias dramatizadas e increpar al interlocutor para lograr un "asentimiento cómplice del lector" (Thanoon, 1991, p. 423). La identificación de ese yo que es a la vez el poeta y el hablante lírico con el lector, se realiza de forma completa. El drama, la problemática y las pasiones humanas del autor son, por extensión, las de cualquier hombre.

\section{Conclusiones}

- Cernuda muestra claramente su postura ante la soledad y la imposibilidad, al ejercer el oficio solitario del farero/poeta, de ser parte de una humanidad que debe amar desde lejos, por quien vive, aunque le resulte una masa abstracta, porque depende de ella y ella depende de él.

- Por su parte, Gil de Biedma se enfrasca en la longeva pelea de "mí contra mí mismo", en una suerte de evidente mutualismo ontológico en el que reconoce las dos entidades que le componen, un moderno Jano que no teme ser quienes es, y quien pone sobre la mesa la vergüenza de ser y el dolor de seguir siendo un ser humano.

\section{Agradecimiento}

Esta publicación obtuvo el financiamiento de: El Fondo de Asistencia Internacional de los Estudiantes y Académicos Noruegos, (SAIH). 


\section{HUMANIDADES}

\section{Lista de referencias}

Cernuda, L. (1958). "Robert Browning”, en Pensamiento poético en la lírica inglesa (siglo XIX), en Cernuda, L. (1994) Prosa I, Obra completa, volumen II, Madrid, Siruela, pp. 392-409.

Cernuda, L. (1958): "Historial de un Libro", en Poesía y Literatura I (1960), en Cernuda, L. Prosa I, Obra completa, volumen II, Madrid, Siruela, 1994, pp. 625-661.

Gil de Biedma, J. (1977): "Como en sí mismo, al fin”, en VV. AA., 3 Luis Cernuda, Universidad de Sevilla, Sevilla, pp. 11-33.

Gottlieb, M. (2014). "El monólogo dramático en la antipoesía de Nicanor Parra". Atenea, No. 510. Pp. 23-29. DOI: http://dx.doi.org/10.4067/So718-04622014000200003

Thanoon, A. J. (1991): El monólogo dramático en la poesía española y contemporánea: (I Luis Cernuda y la segunda generación de posguerra).

Thanoon, A. J. (2009): "Los requisitos formales del género del monólogo dramático". Espéculo. Revista de estudios literarios. Universidad Complutense de Madrid.

Pérez Parejo, R. (2007): "El monólogo dramático en la poesía española del XX: ficción y superación del sujeto lírico confesional del Romanticismo". Espéculo. Revista de estudios literarios. Universidad Complutense de Madrid.

Teruel Benavente, J. (2009).Dialogismo e identidad en la poesía de Jaime Gil de Biedma", en Teatro: Revista de Estudios Culturales / A Journal of Cultural Studies, vol. 23 .

Sáez Aragón, J. (1988). Comentario a 'Soliloquio del farero'. Anales de Filología Hispánica, Vol. 4, 1988-1989, pp. 211-223. 